to be evolved. Some selective procedures now available are little used because the limited number of devices produced which can use them does not justify the tooling expense.

\section{Role of Substrate}

The composition, topography, and method of treatment of the substrate prior to gold plating, are important determinants of the properties of the deposit. Improved properties, such as in porosity and wear resistance, can be achieved by selection of underplates. Post-plate treatments, like the application of certain contact lubricants, can improve sliding performance and may reduce corrosion at pore sites. More careful selection and processing of substrate materials and post-plating treatments will become common for connector contacts.

Gold is indispensable for electrical contacts. The increase in its utilisation will parallel the growth of the electronics field.

\title{
Organic Gold Compounds as Possible Lubricating Oil Additives
}

\section{DEPOSITION OF METAL ON WEARING SURFACES}

To meet the lubrication problems presented by continual advances in the design and efficiency of automobile engines a wide range of chemical additives has been developed over the past thirty or more years. The amounts of these compounds now produced represents a considerable contribution to the whole chemical industry, and a great deal of research has been, and is still being, conducted by their producers. One of the major types of additives, the metal dialkylphosphorodithioates, has achieved wide and large-volume use as a corrosion inhibitor or anti-wear agent, and every leading oil company producing crankcase lubricants markets one or more products containing an additive of this kind - usually zinc dialkylphosphorodithioate - to the extent of a fraction of one per cent.

The precise mechanism by which these compounds reduce corrosion and wear has been investigated by a number of workers in the oil industry, but although it has been established that their effectiveness is directly related to their rate of thermal decomposition, the nature of the surface reaction is not yet fully understood. Efforts have therefore been concentrated on achieving optimum thermal stability by studying the effects of a number of alkyl groups as well as of changes in the metal cation upon both wear and coefficient of friction: It is believed, however, that the decomposition of the additive leads to the formation of a corrosion resistant film by reaction with the metal of the bearing surfaces, so reducing mechanical wear. This reaction naturally gives rise to a certain amount of chemical attack, and it has been one of the objectives of research in this field to develop an additive that would deposit a film of soft metal on the rubbing surfaces without involving them in a chemical reaction.

In the course of an investigation aimed at the deposition of metal on to these surfaces, two members of the Central Research Division of Mobil Research and Development Corporation, Princeton, New Jersey, have now found that, by substituting gold for the generally used zinc as the cation in dialkylphosphorodithioates, a deposit of gold is formed. A preliminary report on this work was published in Nature (1971, 231, May 24th, 87-88) by Joseph J. Dickert and Carleton N. Rowe, while U.S. Patent 3,554,908 also discloses the nature of the development.

\begin{tabular}{|c|c|c|}
\hline \multicolumn{3}{|c|}{ Wear Rate of Steel Pin } \\
\hline $\begin{array}{c}\text { Time } \\
\text { (minutes) }\end{array}$ & $\begin{array}{c}\text { Total wear } \\
\left(\mathrm{cm}^{3} \times 10^{7}\right)\end{array}$ & $\begin{array}{c}\text { Average wear rate } \\
\left(\mathrm{cm}^{3} \mathrm{~cm}^{-1} \times 10^{12}\right)\end{array}$ \\
\hline 15 & 3.9 & 43.0 \\
30 & 5.6 & 30.0 \\
60 & 5.6 & 15.0 \\
300 & 7.8 & 4.2 \\
1000 & 8.7 & 1.5 \\
\hline
\end{tabular}

Using two types of wear testing apparatus, a pin-on-disc machine and a four-ball machine, they found that gold was deposited on the wear scars of the steel pins and of the steel balls from a solution of gold dineopentylphosphorodithioate in $n$-hexadecane. The gold films were clearly visible and were conclusively identified by X-ray diffraction. More importantly, the average wear rate was found to diminish with time and to become extremely small after only a short period of testing. An example of this effect is given in the table, which shows the average wear rate expressed as volume per unit sliding distance, using a separate pin for each experiment.

While the mechanism is not understood, the evidence suggests that the local surface temperature on the rubbing surfaces contributes to the deposition of the gold in the contact area, since no deposition was found to occur elsewhere. The gold was seen to form preferentially on the surface in constant contact - the one having the sustained high surface temperature the pin or the stationary balls. In effect the system appears to become one of steel sliding against gold, and the great importance of the work lies in the fact that any loss of gold brought about by wear is replenished by further deposition. Thus the system achieves a balance of film wear and film formation depending upon the severity of operating conditions, and with proper balance the bearing surface can survive for as long as the new additive is present in solution.

L. B. H. 